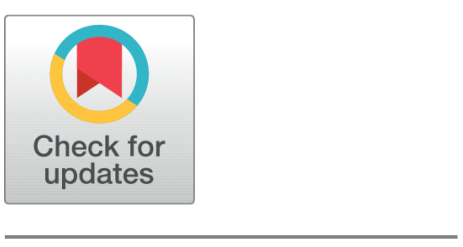

OPEN ACCESS

Received: 28-05-2020

Accepted: 07-08-2020

Published: 21-08-2020

Editor: Dr. Natarajan Gajendran

Citation: Channa F, Kumar M, Mahmood Soomro A, Farhan M (2020) Strategically plug-in electrical vehicle load management in radial distribution system (A case study). Indian Journal of Science and Technology 13(30): 3113-3127. https ://doi.org/10.17485/IJST/v13i30.757

* Corresponding author.

Tel: +92-3072809964

Faizanchanna26@gmail.com

Funding: None

Competing Interests: None

Copyright: @ 2020 Channa et al. This is an open access article distributed under the terms of the Creative Commons Attribution License, which permits unrestricted use, distribution, and reproduction in any medium, provided the original author and source are credited.

Published By Indian Society for Education and Environment (iSee)

ISSN

Print: 0974-6846

Electronic: 0974-5645

\section{Strategically plug-in electrical vehicle load management in radial distribution system (A case study)}

\author{
Faizan Channa ${ }^{1 *}$, Mahesh Kumar ${ }^{1}$, Amir Mahmood Soomro', \\ Muhammad Farhan ${ }^{2}$ \\ 1 Institute of Information and Communication Technologies, Mehran University of \\ Engineering and Technology, Jamshoro, Tel.: +92-3072809964 \\ 2 Department Of Electrical Engineering, Government College, University of Faisalabad, \\ Pakistan
}

\section{Abstract}

Objectives: To present a Plug in electric vehicle load model to integrate its maximum loading and distributed generations (DGs) units by maintaining maximum voltage profile value and lesser active and reactive power losses drop in the distribution system. Methods/Statistical analysis: This study comprises in two phases, in first phase IEEE 33-bus radial distribution system with standard data available is simulated using ETAP software. In the second phase, different PEV load model scenario and distributed generation units will be designed and integrated. At each scenario, the voltage profile, active and reactive power losses are observed and strategy is proposed in the manuscript. Findings: The test system gives convincing results even with adoption of new generation and plug-in electrical vehicles load without violating system performance. Novelty/Applications: The proposed study is best suited for practical application of distribution system such as introduction of DG units (i.e. solar PV) and plug-in electrical vehicle load with proper loading. Additionally, this study uses backward-forward sweep method to manage PEVs load with optimum size of DG units; it improves system losses and minimum per unit bus voltage within acceptable limits, unlike other studies. Result of this study allows to use smaller size of DG units with minimum cost.

Keywords: Plug-in electric vehicle; radial distribution system; recharging stations; load management; distributed generation

\section{Introduction}

Electric vehicles (EV) load model is an important parameter to solve power flow of the grid. In addition, size and position of EVs load can be considered in optimal requirement for minimizing impact on the grid. Further, power flow analysis under various electric vehicle load models are presented, these models are based on modified backward and forward sweep method ${ }^{(1)}$. Demand response(DR) programs and Smart charging and discharging of PEV are examined for enhancing the reliability of radial distribution system with the help of particle swam optimization(PSO) algorithm. 
Further, priority is given to DR and PEVs in order to improve reliability and analyzing characteristics of distribution systems ${ }^{(2)}$. An impact of PEVs on distribution network voltage unbalance is investigated. Additionally, voltage unbalance factor (VUF) is reduced optimally by choosing state (charging or discharging) of PEVs. Further, effect of coordinated or uncoordinated charging of electrical vehicle is examined ${ }^{(3)}$. A decentralized method is proposed to avoid overloading on feeders. By applying the suggested technique proposed solution converges and satisfies the limit of the feeder lines ${ }^{(4)}$. EVs and distributed renewable resources (DRR) are used to achieve certain goals: like eco-friendly resources, reliability of demand and sustainability of power system. To accomplish mentioned objectives DRR and EVs should be implemented. Further, two stage technique is proposed to allocate EV parking lots and DRR in distribution system. Moreover, two techniques are used to solve optimization problem: Genetic algorithm (GA) and particle swarm optimization (PSO) algorithm ${ }^{(5)}$. To- efficiently use vehicle to grid technique by adding project based battery reduction cost to embed into micro grid, two energy management planning is suggested for addition of vehicle to grid into micro grid on basis of forecast accurate power supply and demand, these strategies are further implemented on multi-agent system ${ }^{(6)}$. The process of charging introduce oscillations in power system that reduces stability, this process can be examined by comparing EV load and normal power system load ${ }^{(7)}$. Therefore problem need to be solved of EV that affect various buses of electric power system, charging process of EV create voltage imbalance, voltage difference between two phases ${ }^{(8)}$. Another aspect to consider EV's in future is that oil reserves are depleting day by day therefore electric vehicles have been introduced that can be recharged at recharging stations, but process of recharging can affect electric power system. Other benefits to use EV's are that they are relatively cheaper to run and their maintenance cost is also low, beneficial for environment ${ }^{(9)}$. Bidirectional vehicle to grid method is introduced to use the energy from EV in a parking lot, this system is checked in real power distribution network load, from simulated results it was known that this technique provide savings and reducing peak demand of connected grids ${ }^{(10)}$. A composed distribution location marginal pricing method to make less severe hindrance due to EV load in power system, in this method distribution system operator (DSO) find distribution location based marginal prices, function of DSO is to manage distribution network, operating at low and medium voltage ${ }^{(11)}$.

\section{Methodology}

A backward forward sweep technique is used for simulation, standard IEEE 33-bus RDS is considered for simulation, IEEE 33bus system is designed with its standard electrical parameter by using ETAP software. Simulation is designed in such a way that $\mathrm{PEV}$ (plug in electric vehicle) is connected with recharging stations (RS) to charge its battery, in this study one recharging station contains of 8 number of PEVs, means maximum 8 PEVs can be connected to single RS. Generally battery of electrical vehicles is rated in $\mathrm{kWh}, \mathrm{kWh}$ is divided with number of hours to get $\mathrm{kW}$ rating of single $\mathrm{PEV}$, by getting $\mathrm{kW}$ rating further simulation is carried out in ETAP software in which main components of RDS are buses, branches, utility grid and load. It consists of 33 buses, 32 branches. Load of single RS is combination of load of 8 number of PEVs, further RS are connected to different number of buses, as the load on system is increased system active and reactive power losses are increased. In addition of management of load, distributed generators (PV array) are installed at certain buses to compensate system losses. The methodology for simulation of IEEE 33-bus system with EV load model consists of following steps.

The methodology for simulation of IEEE 33-bus system with EV load model consists of the following steps:

Step1. Preparation of the network that can be used as branch numbering method.

Step2. Deciding load of single PEV unit and complete load of single recharging station.

Step3. Integrating recharging stations at certain buses of system.

Step4. Integrating distributed generations (PV cells) within same system for compensation of losses and load management.

Step5. Run load flow analysis and to obtain result.

\subsection{Forward sweep}

Forward Sweep (FS) method is based on Kirchhoff's voltage law (KVL) that is used to determine voltage with most recent branch currents, with this method, nodal voltage is computed at each node, the value is updated in FS by starting from slack bus towards the end of network. Node voltage is computed by making difference of the last node $\mathrm{V}_{L 1}{ }^{\mathrm{K}}$, from voltage drop in transmission line $V_{L 2}{ }^{\mathrm{K}}$ :

$$
\mathrm{V}_{\mathrm{L} 2} \mathrm{~K}=\mathrm{V}_{\mathrm{L} 1} \mathrm{~K}-\mathrm{I}_{\mathrm{L}} \mathrm{Z}_{\mathrm{L}} \mathrm{K}
$$

Where $\mathrm{V}_{L 1}{ }^{\mathrm{K}}$ is sending end node voltage, $V_{L 2}{ }^{\mathrm{K}}$ is receiving end node voltage, $\mathrm{I}_{L} \mathrm{Z}_{L}{ }^{\mathrm{K}}$ is voltage drop in transmission. 


\subsection{Backward sweep}

Backward Sweep is based on KCL, it is used to determine current with most recent voltage updates. The direction of current in branch has a backward direction, that starts from backward direction towards starting slack bus, with the help of equations can be explained as.

$$
S_{i}=\mathrm{P}_{i}+\mathrm{jQ}
$$

Equation (equ (2)) is load on power system, where $S_{i}$ apparent power, $\mathrm{P}_{i}$ is actual power and Qi is reactive power of system.

$$
P_{i, E V}=P_{i}+P_{E V}
$$

When EVs are connected, active power losses on network is shown in equ (3). Where ${ }_{i, E V}$ istotal active power losses of network load and $\mathrm{EV}, \mathrm{P}_{i}$ active power losses due to network load, $\mathrm{P}_{E V}$ is active power losses due to EV load.

$$
Q_{i, E V}=Q_{i}+Q_{E V}
$$

When EVs are connected, reactive power losses on network is shown in equ (4). Where ${ }_{i, E V}$ is total reactive power losses due to network load and EV load, $\mathrm{Q}_{i}$ is reactive power losses due to network load, $\mathrm{Q}_{E V}$ is reactive power

$$
S_{i}=\mathrm{P}_{i, \mathrm{EV}}+\mathrm{Q}_{i, \mathrm{EV}}
$$

Total load on power system can be rewritten as equ (5).

\subsection{PEV load model calculations}

In this research type of PEV load model is invariable current load, it consists of active power and reactive power achieved by exponential load, which is founded on typical type of general load exponential indices $(\alpha)$ as shown in (eq. 6). $\alpha$ of this PEV load model is equal to 1 for real power, wattles power is defined as equal to 0 (unity power factor), battery of PEV is rated in kWh. E:g BMW i3 PEV 42kWh battery, If a battery takes $42 \mathrm{kWh}$ for full charge in 4 hours, then continuous load it takes till full charge is $10.5 \mathrm{~kW}$. Single PEV $=10.5 \mathrm{~kW}$, One recharging station $(\mathrm{RS})=8 \mathrm{PEVs}$, total load of one $\mathrm{RS}=8 \times 10.5 \mathrm{~kW}=84 \mathrm{~kW}$. Following equations are used for the calculation of active and reactive power.

$$
\begin{gathered}
P_{E V}=P o\left(\frac{V_{i}}{V_{0}}\right)^{\alpha} \\
Q_{E V}=0
\end{gathered}
$$

Eqs (6) and (7) shows active and reactive power of constant current load model respectively.

\section{Case studies}

This paper carries 5 case studies, including the size of DG, the location of DG with different electrical vehicle load levels. Each case study has been designed by observing the power losses on that bus, the maximum loading at that bus or minimum voltage level. At final, it was observed which case will be more beneficial practically.

1. RDS with 1 DG: $70 \%$ of load size connected at bus 06 .

2. RDS with 1 DG: $30 \%$ of load size connected bus at 18 .

3. RDS with 1 DG: $30 \%$ of load size connected at bus 32 .

4. RDS with 2 DGs: DG 1 with $70 \%$ of load size connected at bus 06 , DG 2 with $30 \%$ of load size connected at bus 32 .

5. RDS with 2 DGs: DG 1 with $30 \%$ of load size connected at bus 18, DG 2 with $30 \%$ of load size connected at bus 32 .

\subsection{IEEE 33-BUS RDS load and PEVs load}

- Total load of IEEE 33-bus RDN 3.72MW for active power, 2.3MVAR for reactive power losses.

- By integrating PEVs load in RDN, load of 1.08MW is increased. Therefore, \%DG of total load size is.....

- $70 \%$ of $4.80 \mathrm{MW}$ is $3.36 \mathrm{MW}$.

- $50 \%$ of $4.80 \mathrm{MW}$ is $2.4 \mathrm{MW}$.

- $30 \%$ of $4.80 \mathrm{MW}$ is $1.44 \mathrm{MW}$. 


\section{Results and Discussions}

\subsection{Case 1: RDS with 1 DG: 70\% Of system load size connected at bus \#06}

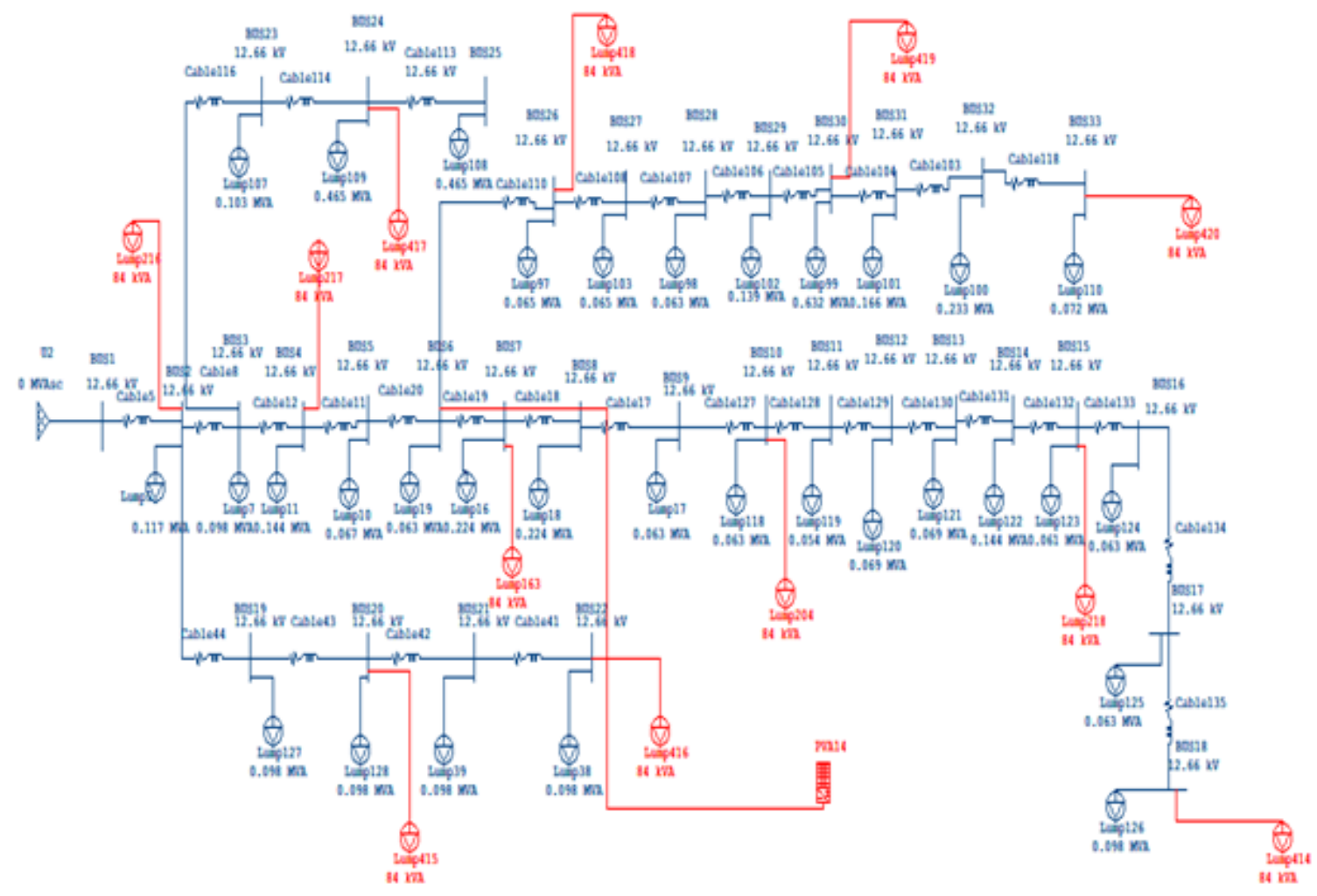

Fig 1. IEEE 33-bus with pev load and dg

Figure 1 shows ETAP simulation model of IEEE 33-bus RDS with PEV load integration at different buses and 1 DG with $70 \%$ of load size connected at bus \#06.

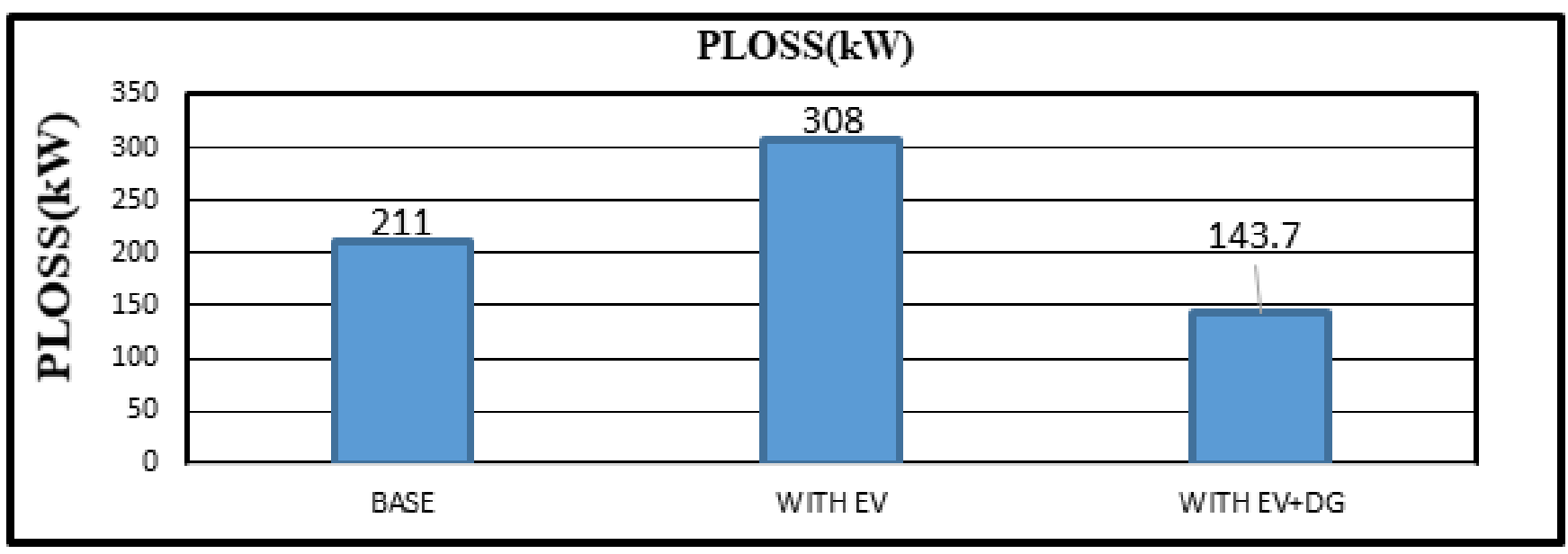

Fig 2. Active power losses 
In Figure 2, base case active power losses are $211 \mathrm{~kW}$ with integration of PEVs load, active power losses increased to $308 \mathrm{~kW}$, after addition of 70\% DG of load size connected at bus\#06 losses are reduced to $143.7 \mathrm{~kW}$.

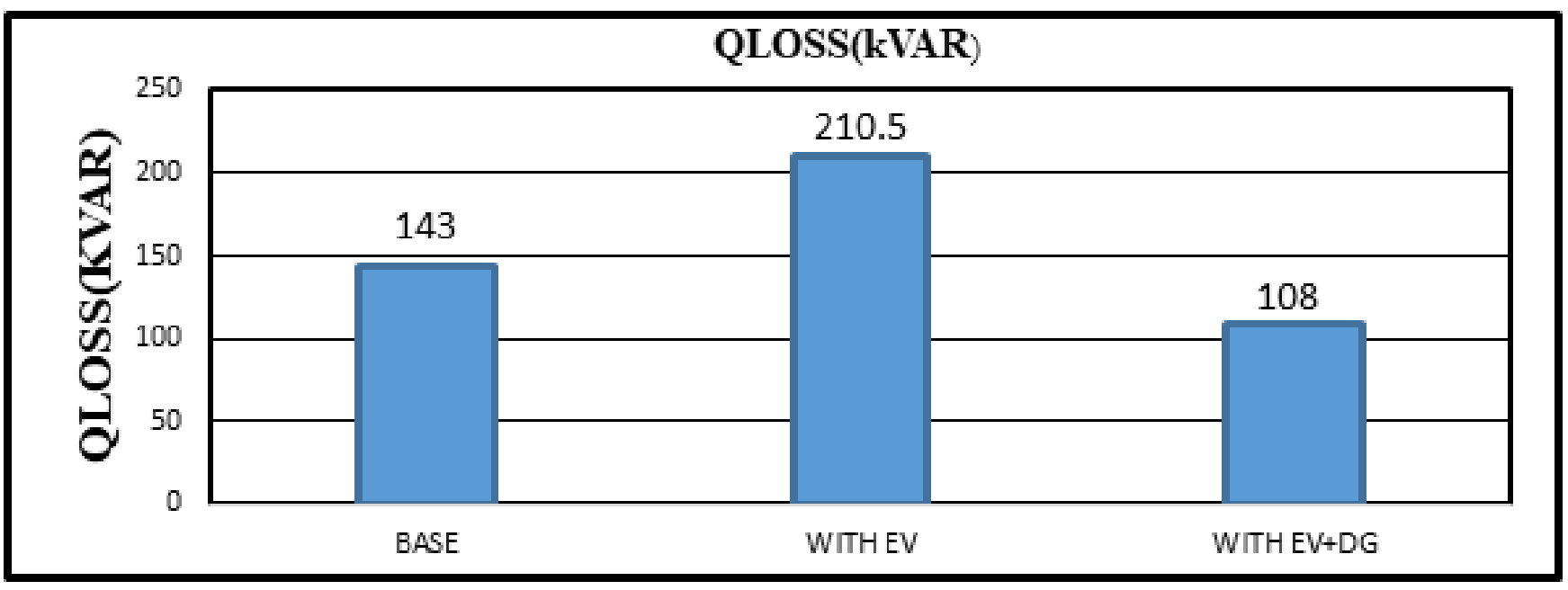

Fig 3. Reactive power losses

In Figure 3, base case reactive power losses are 143KVAR with integration of PEVs load, KVAR losses increased to 210.5KVAR, after addition of $1 \mathrm{DG}$ with $70 \%$ of load size connected at bus\#06 losses are reduced to 108KVAR.

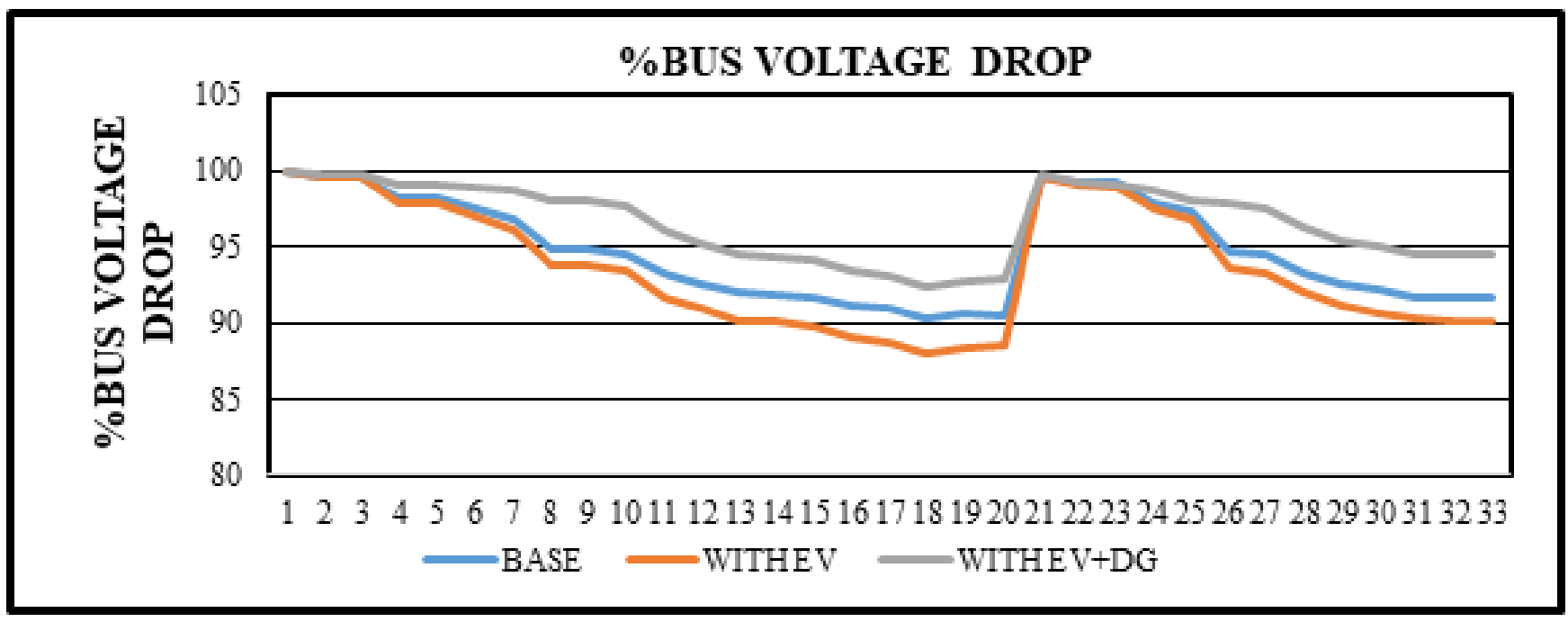

Fig 4. \% BUS voltage drop across each bus

Figure 4 shows \% Bus voltage drop across each bus in base case, after integration of PEVs load and 1 DG with $70 \%$ of load size connected at bus \#06. 


\subsection{Case 2: RDS with 1 DG: $30 \%$ Of system load size connected at bus\#18}

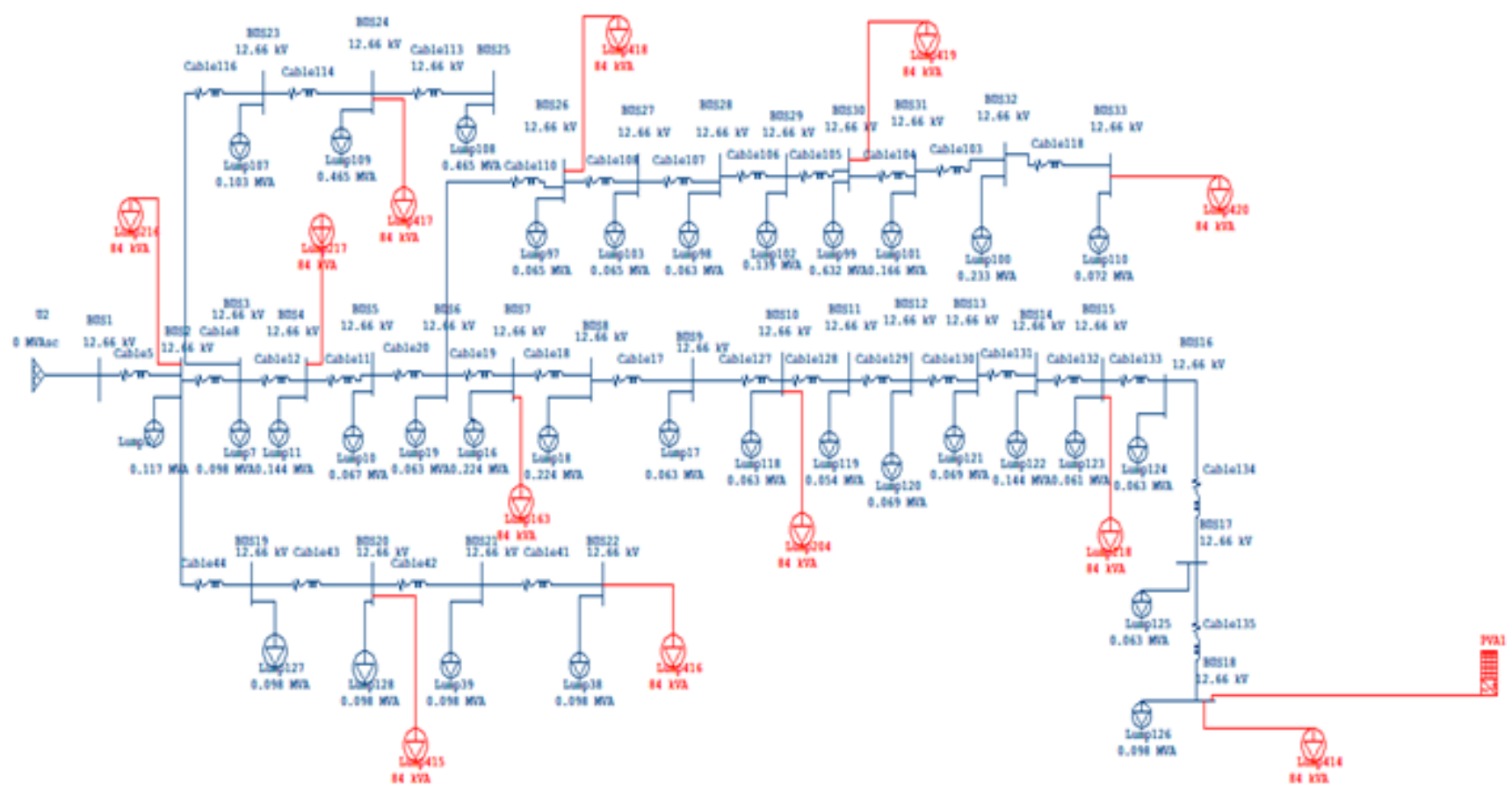

Fig 5. IEEE33-bus with pev load and dg

Figure 5 shows ETAP simulation model of IEE 33-bus RDS with PEV load integration at different buses and 1 DG with 30\% of load size connected at bus \#18

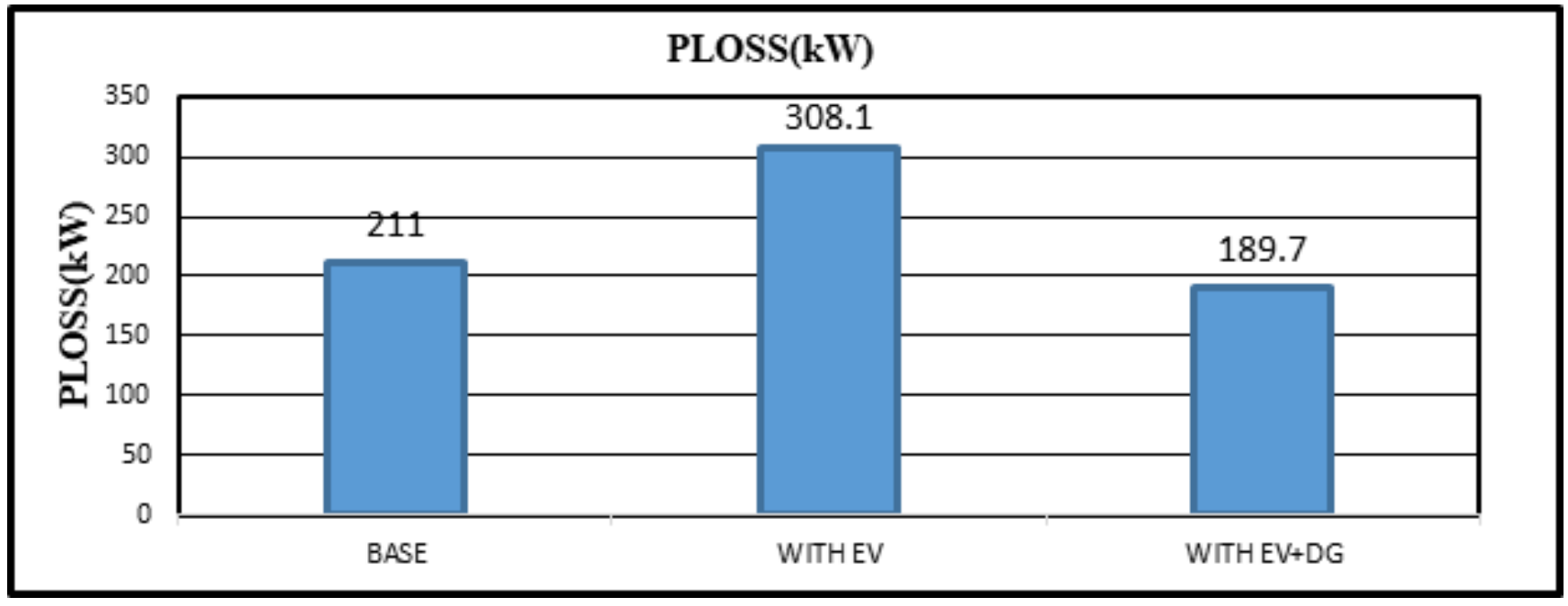

Fig 6. Active power losses

In Figure 6, base case active power losses are $211 \mathrm{~kW}$ with integration of PEV load active power losses increased to $308 \mathrm{~kW}$, after addition of DG with $30 \%$ of load size at bus\# 18 losses reduced to $189.7 \mathrm{~kW}$. 


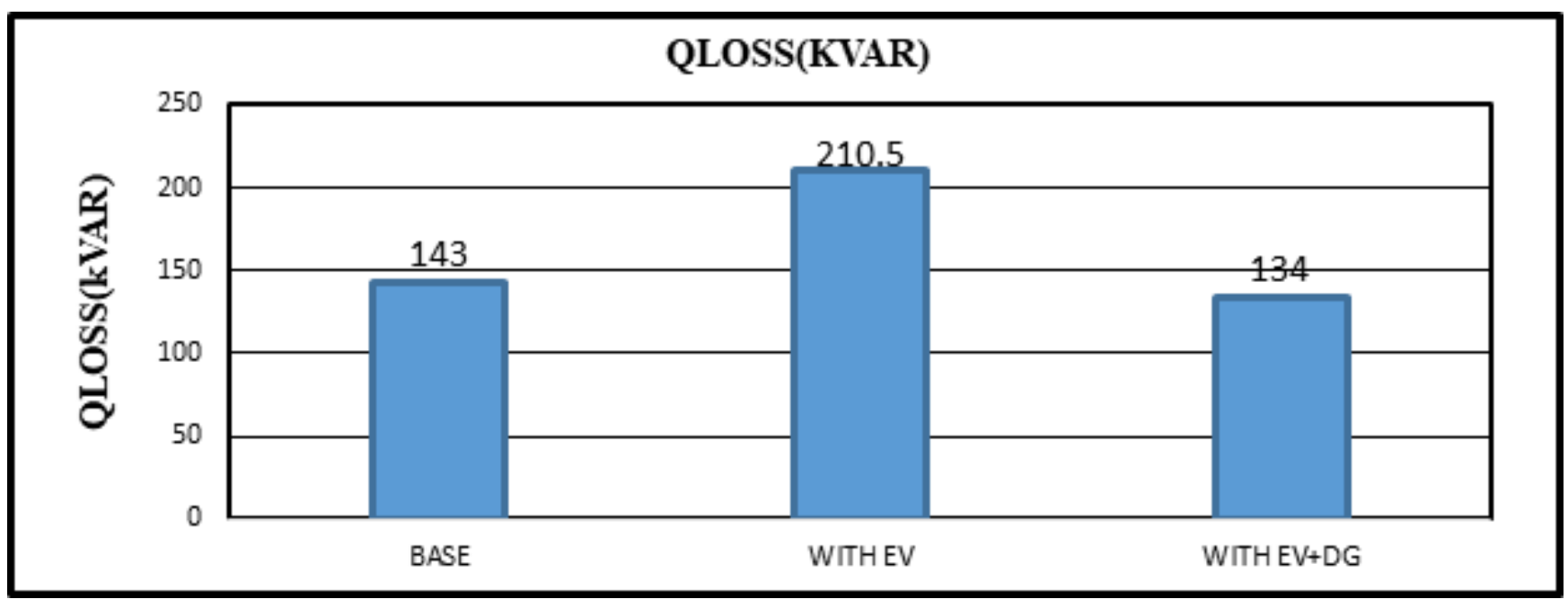

Fig 7. Reactive power losses

In Figure 7, base case reactive power losses are 143KVAR with integration of PEVs load, KVAR losses increased to 210.5KVAR, after addition of DG with $30 \%$ of load size connected at bus\#18, losses reduced to 134KVAR.

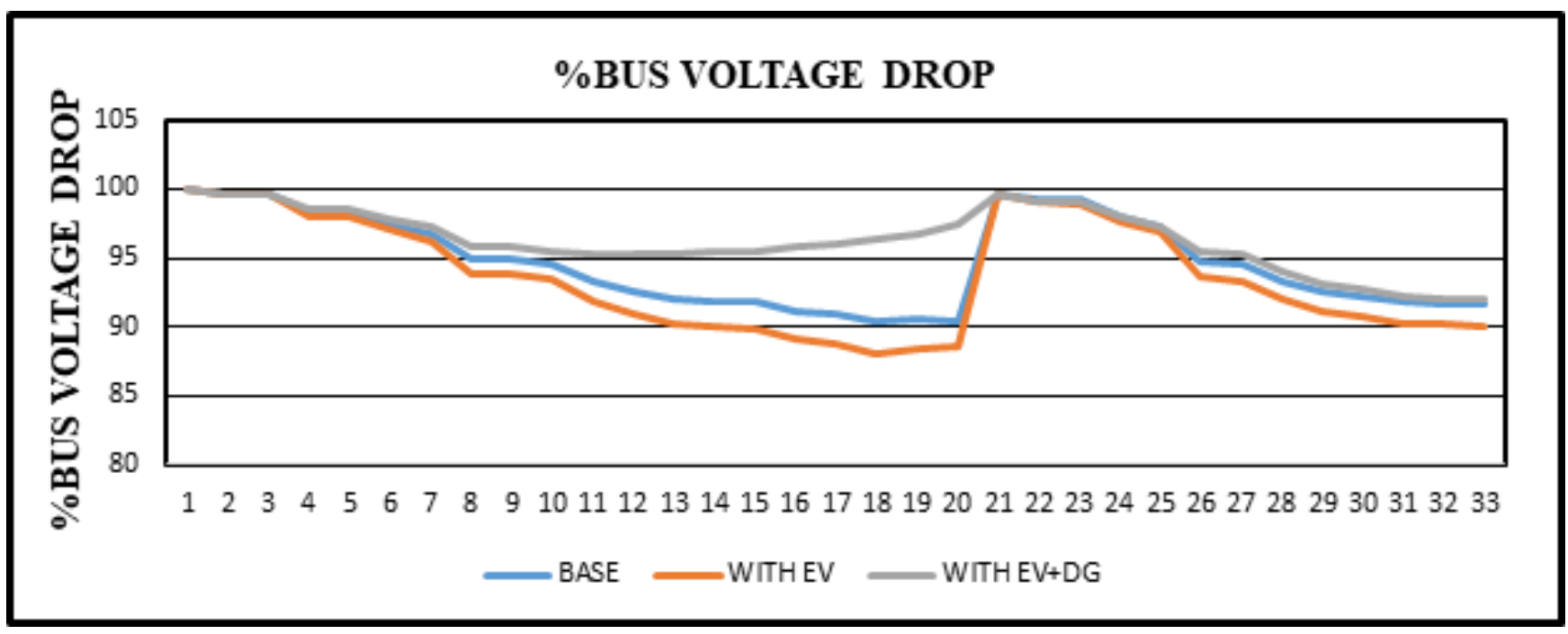

Fig 8. \% BUS voltage drop across each bus

Figure 8 shows \%Bus voltage drop across each bus in base case, after integration of PEVs load and 1 DG with 30\% of load size connected at bus \#18. 


\subsection{CASE 3: RDS with 1 DG: $30 \%$ Of system load size connected at bus \#32}

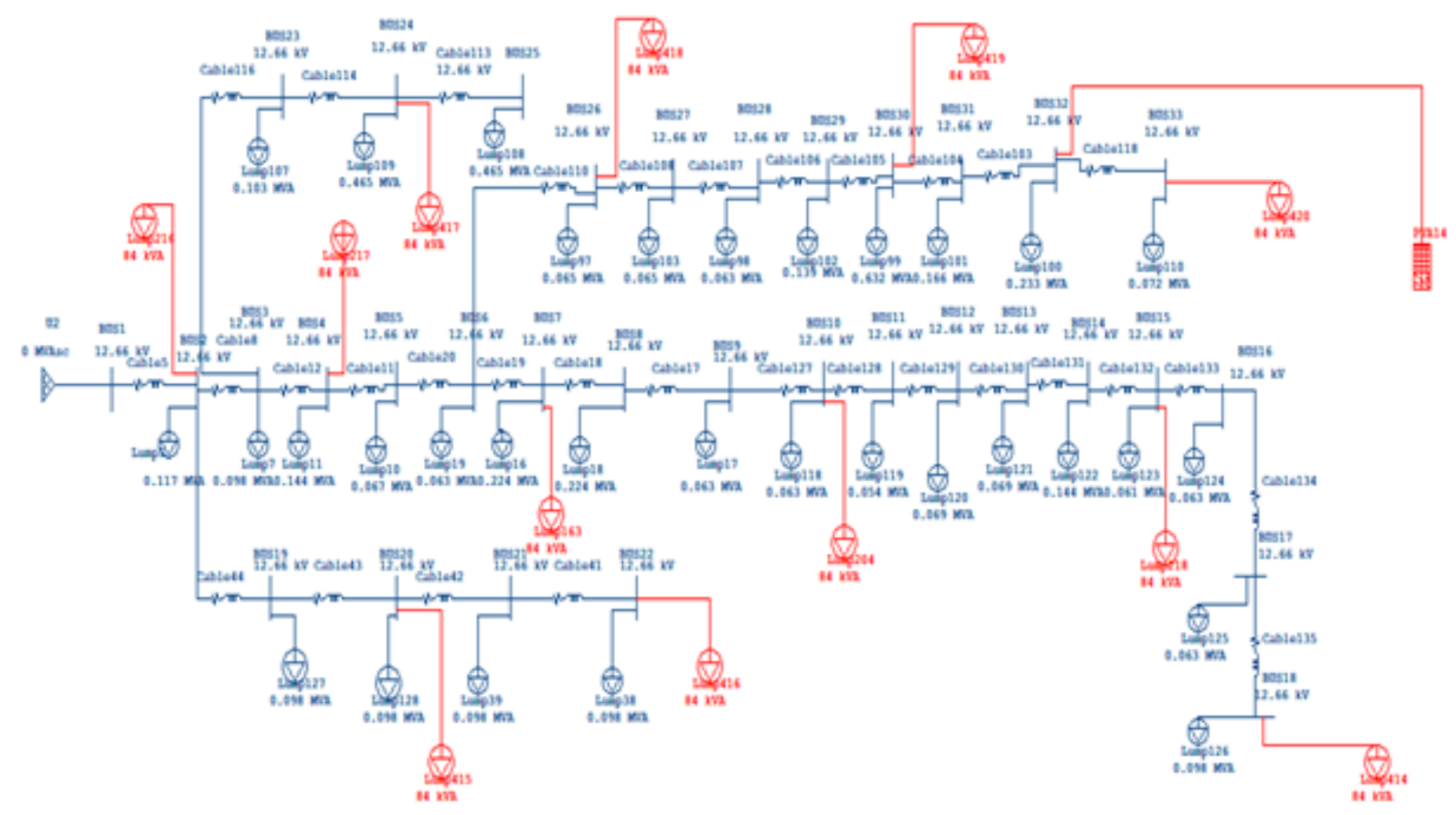

Fig 9. IEEE33-bus with pev load and dg

Figure 9 shows ETAP simulation model of IEE 33-bus RDS with PEV load integration at different buses and 1 DG with 30\% of load size connected at bus \#18.

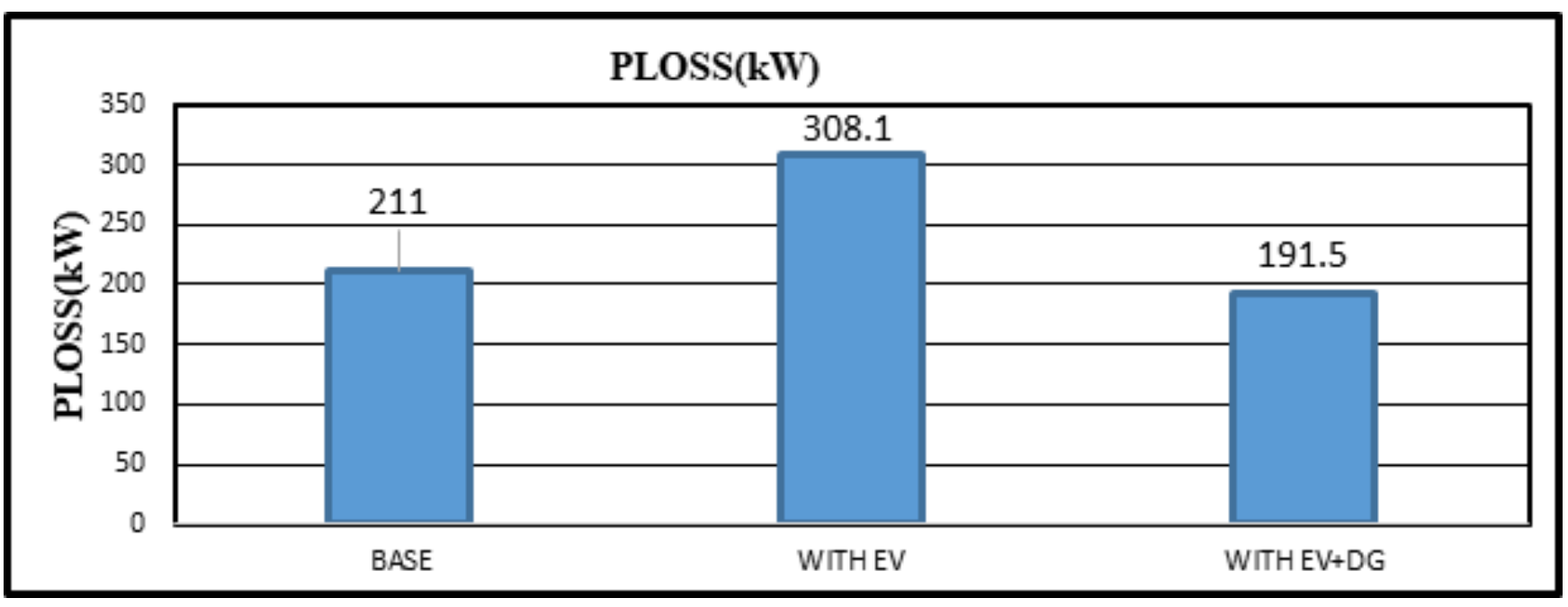

Fig 10. Active power losses

In Figure 10 , base case active power losses are $211 \mathrm{~kW}$ with integration of PEVs load, active power losses increased to $308 \mathrm{~kW}$, after addition of DG with $30 \%$ load size at bus\#32 losses reduced to $191.5 \mathrm{~kW}$. 


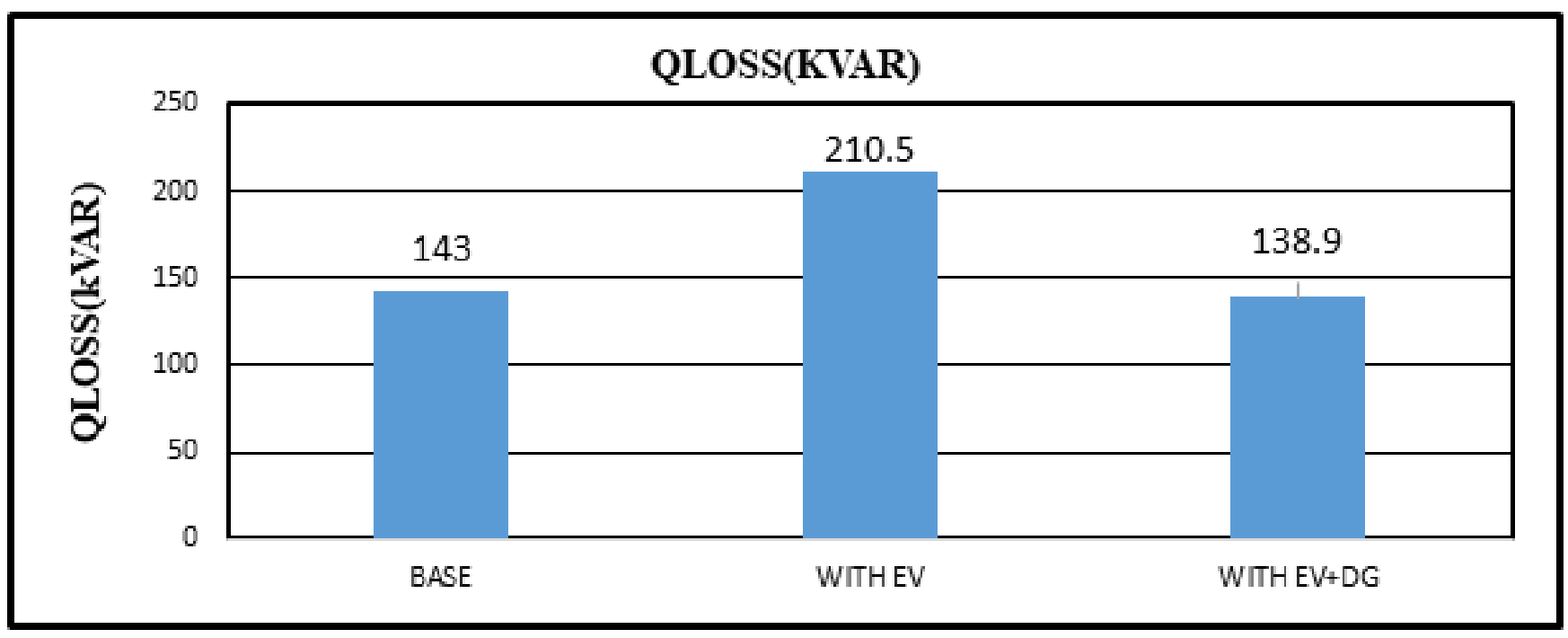

Fig 11. Reactive power losses

In Figure 11, base case reactive power losses are 143KVAR with integration of PEV load losses increased to $210.5 \mathrm{KVAR}$, after addition of DG with $30 \%$ of load size at bus\#32, KVAR losses reduced to 138.9KVAR.

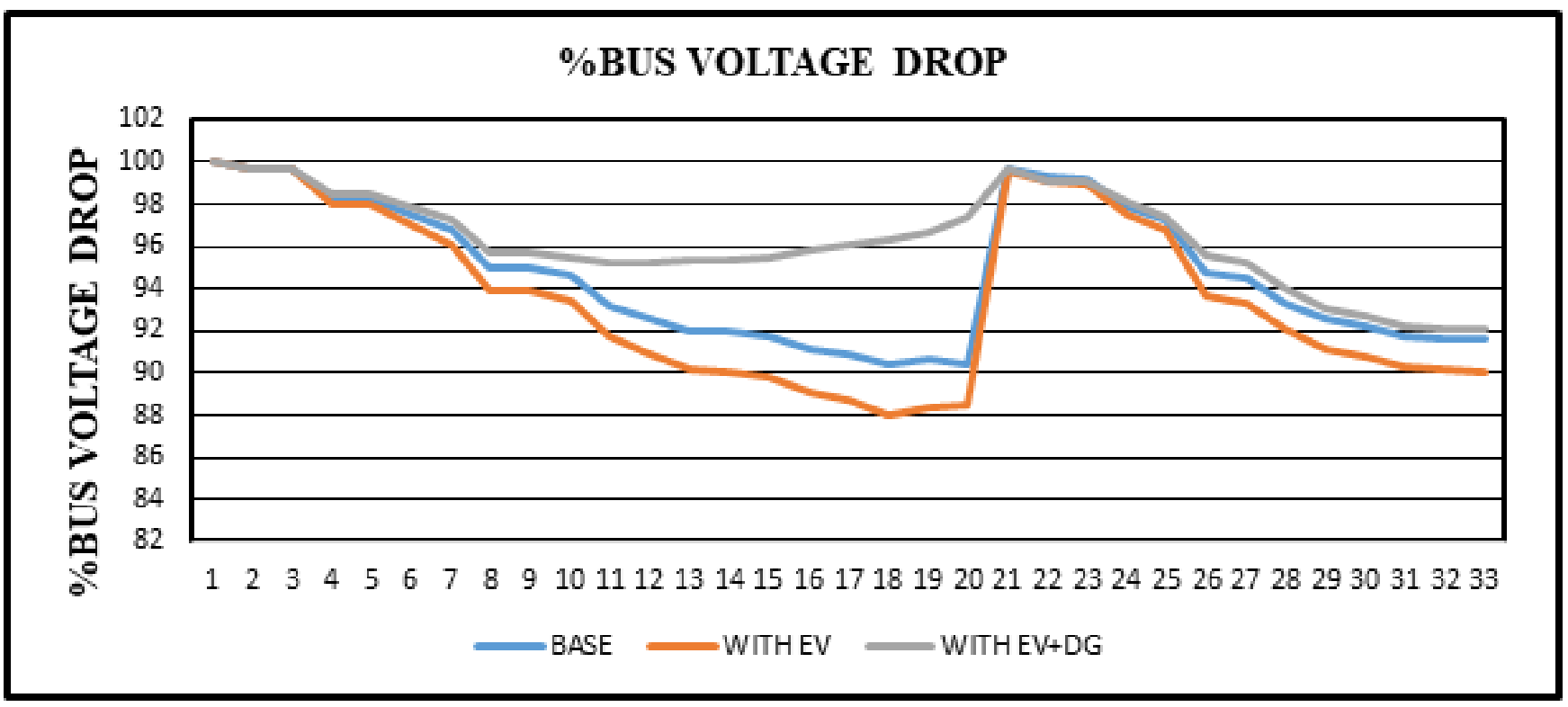

Fig 12. \% BUS voltage drop acrosseach bus

Figure 12 shows \%Bus voltage drop across each bus in base case, after integration of PEVs load and DG with $30 \%$ of load size connected at bus \#32. 


\subsection{CASE 4: RDS with 2 DGs: DG 1 With 70\% Of system load size connected at Bus \#06, DG 2 with $30 \%$ Of load size connected at BUS\#32}

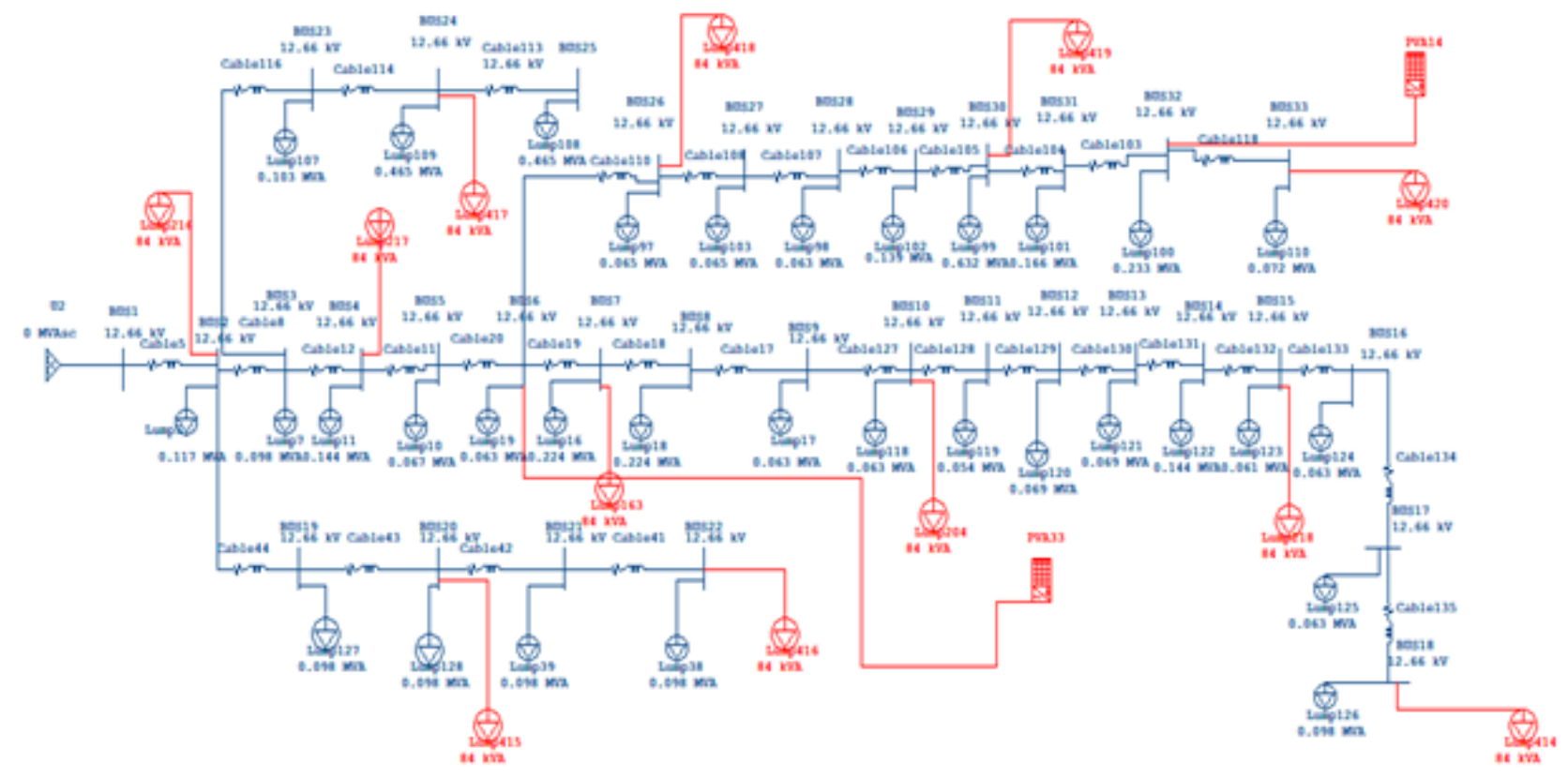

Fig 13. IEEE33-bus with pev load and dg

Figure 13 shows ETAP simulation model of IEEE 33-bus RDS with PEV load integration at different buses and 1 DG with $30 \%$ of load size connected at bus \#18.

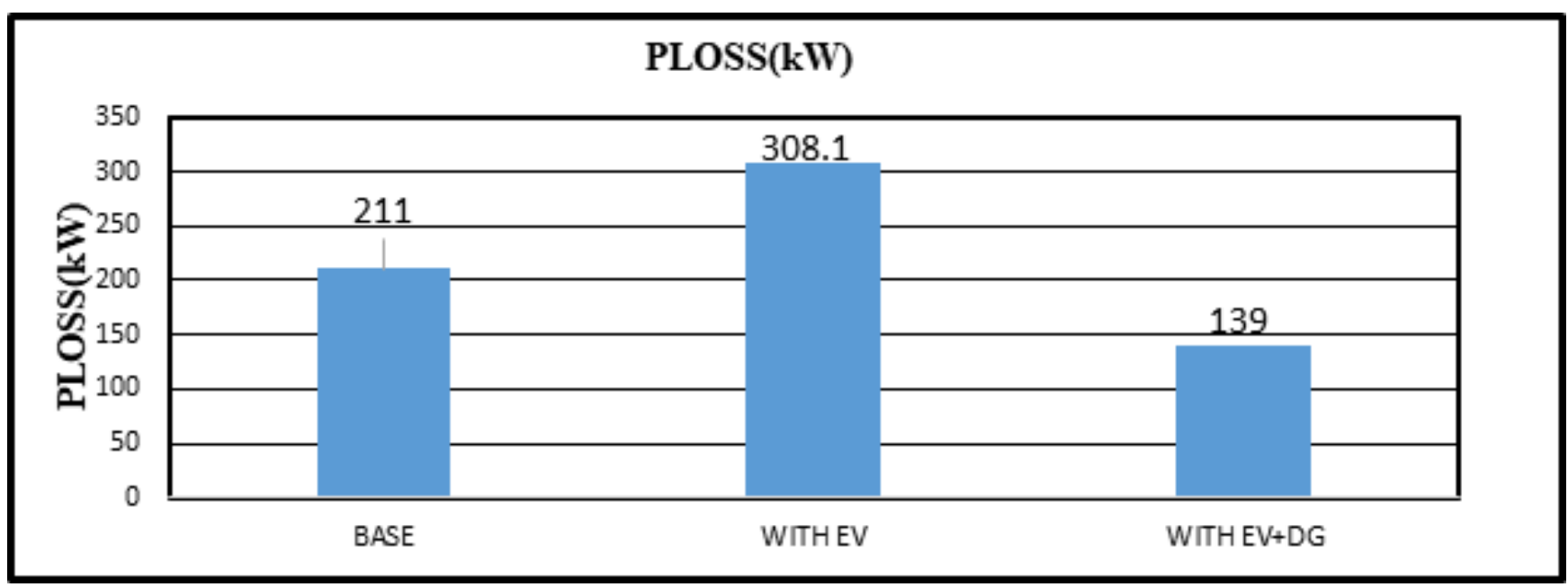

Fig 14. Active power losses

In Figure 14 , base case active power losses are $211 \mathrm{~kW}$, with integration of PEVs load, active power losses increased to $308 \mathrm{~kW}$, after addition of 2 DGs, DG 1 with 70\% of load size connected at bus\#06 and DG 2 with 30\% of load size connected at bus\#32 then active power losses reduced to $139 \mathrm{~kW}$. 


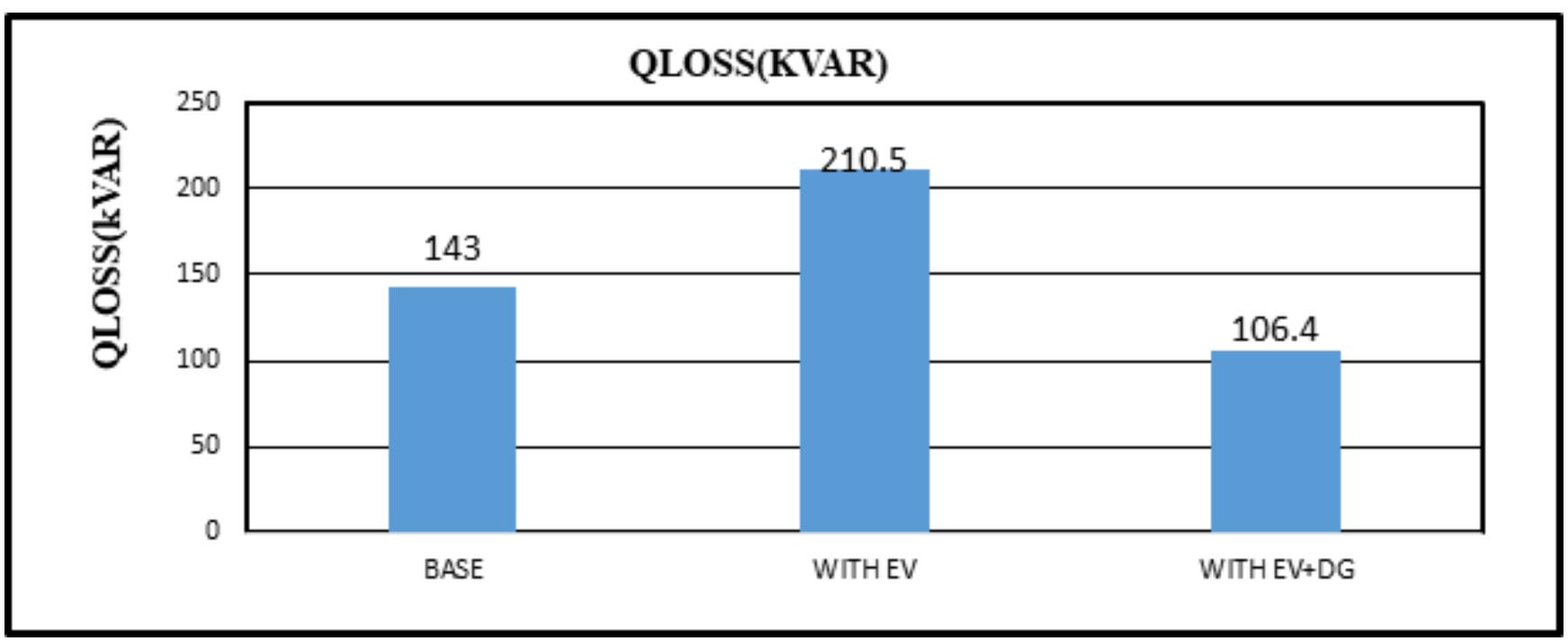

Fig 15. Reactive power losses

In Figure 15 , base case reactive power losses are 143KVAR, with integration of PEV load, losses increased to 210KVAR, after addition of 2 DGs, DG 1 with 70\% DG of load size connected at bus\#06 and DG 2 with $30 \%$ of load size connected at bus\#32 losses reduced to 106.4KVAR.

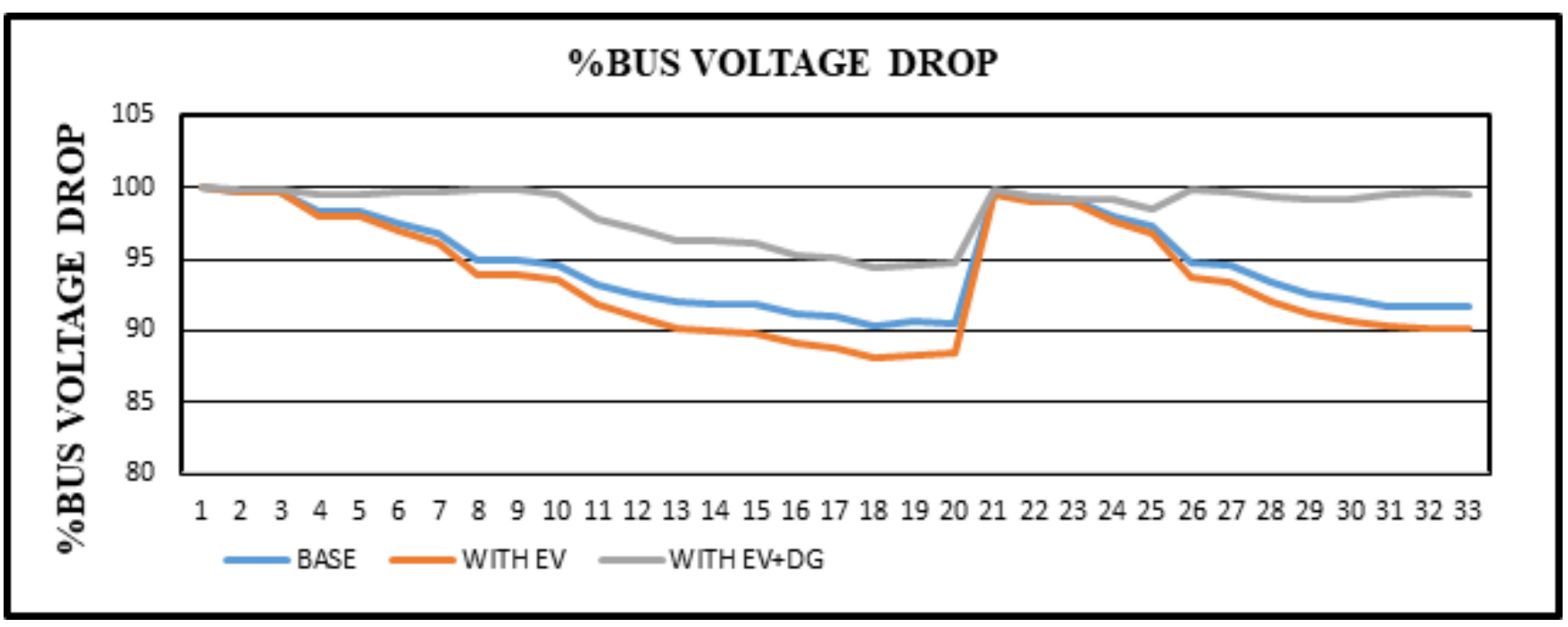

Fig 16. \%BUS voltage drop across each bus

Figure 16 shows \%Bus voltage drop across each bus in base case, after integration of PEV load and 2 DGs, DG 1 with 70\% of load size connected at bus\#06, DG 2 with $30 \%$ of load size connected at bus \#32. 


\subsection{CASE 5: RDS with 2 DGs: DG 1 with $30 \%$ Of system load size connected at BUS\#18, DG 2 with $30 \%$ Of load size connected at BUS\#32}

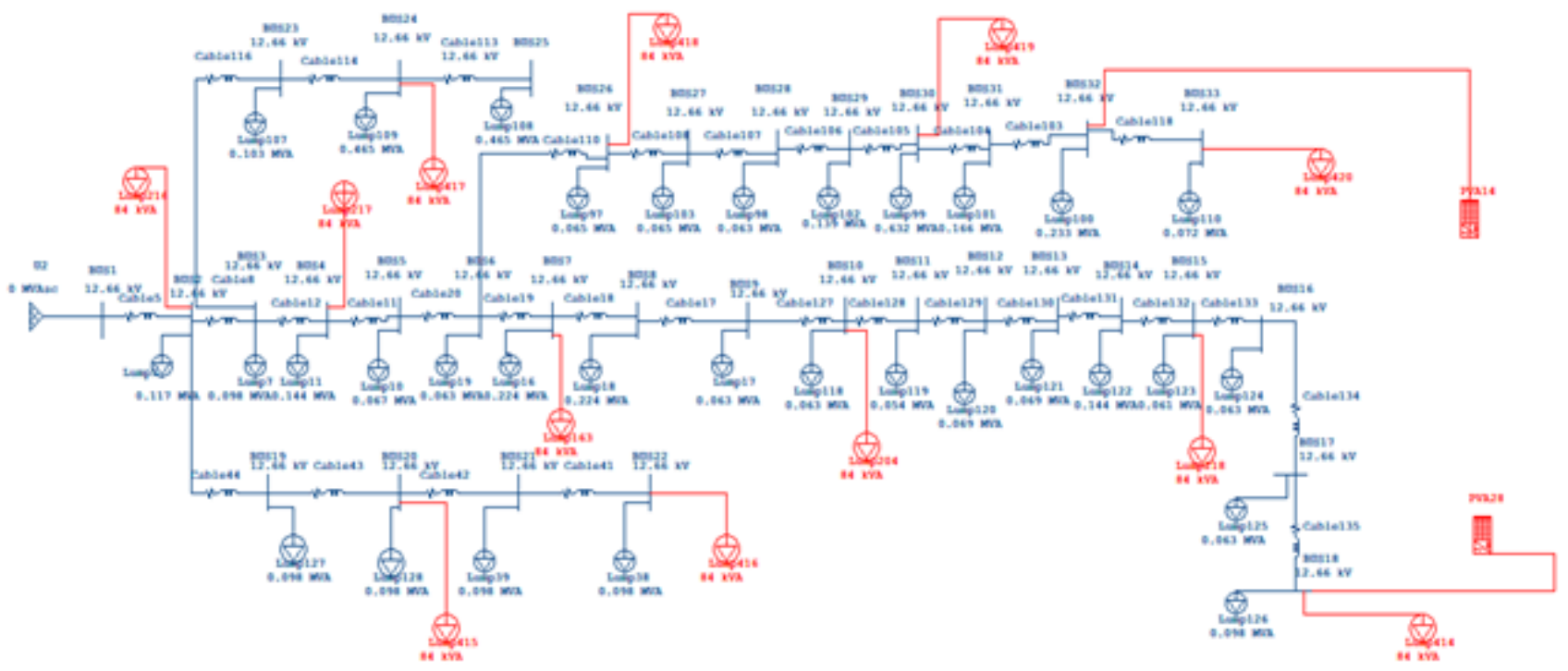

Fig 17. IEEE 33-bus with pev load and dg

Figure 17 shows ETAP simulation model of IEEE 33-bus RDS with PEV load integration at different buses and 2 DGs, DG 1 with $30 \%$ of load size connected at bus \#18, DG 2 with $30 \%$ of load size connected at bus 32 .

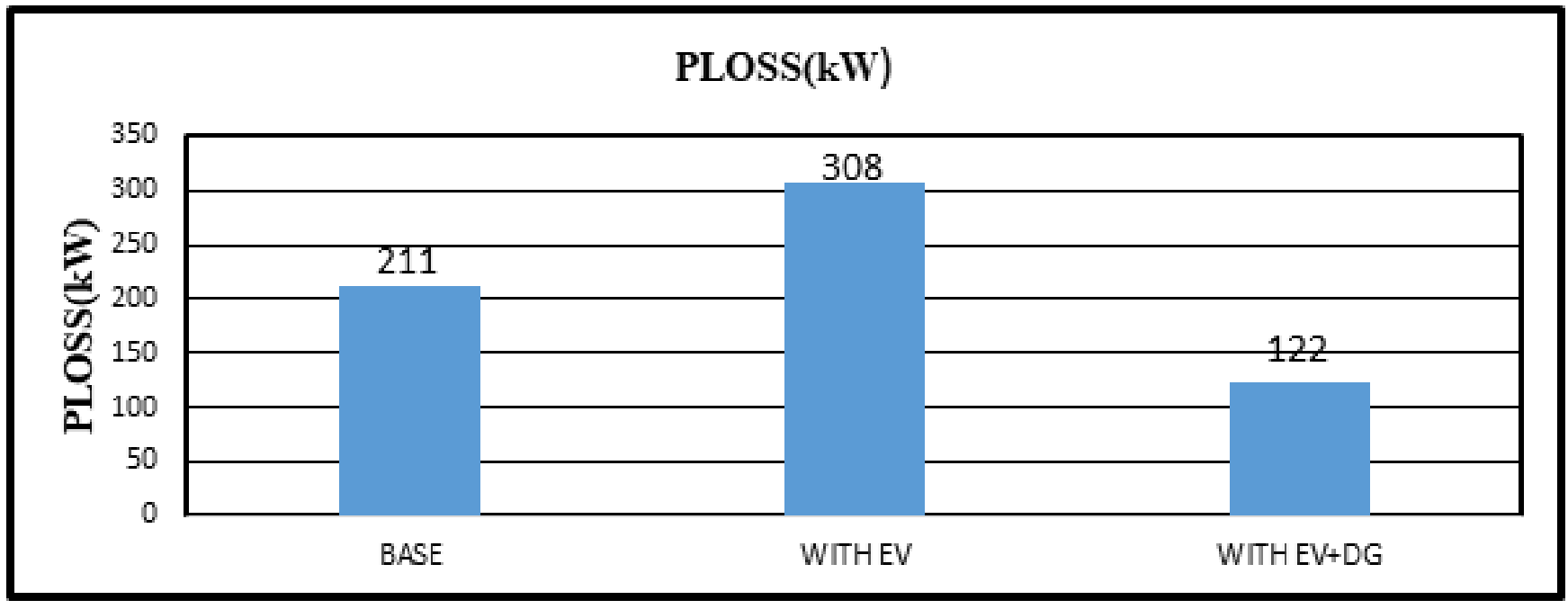

Fig 18. Active power losses

In Figure 18, base case active power losses are $211 \mathrm{~kW}$, with integration of PEV load, active power losses increased to $308 \mathrm{~kW}$, after addition 2 DGs, DG 1 with $30 \%$ of load size connected at bus\#18, DG 2 with $30 \%$ of load size connected at bus\#32, active power losses losses reduced to $122 \mathrm{~kW}$. 


\section{QLOSS(KVAR)}

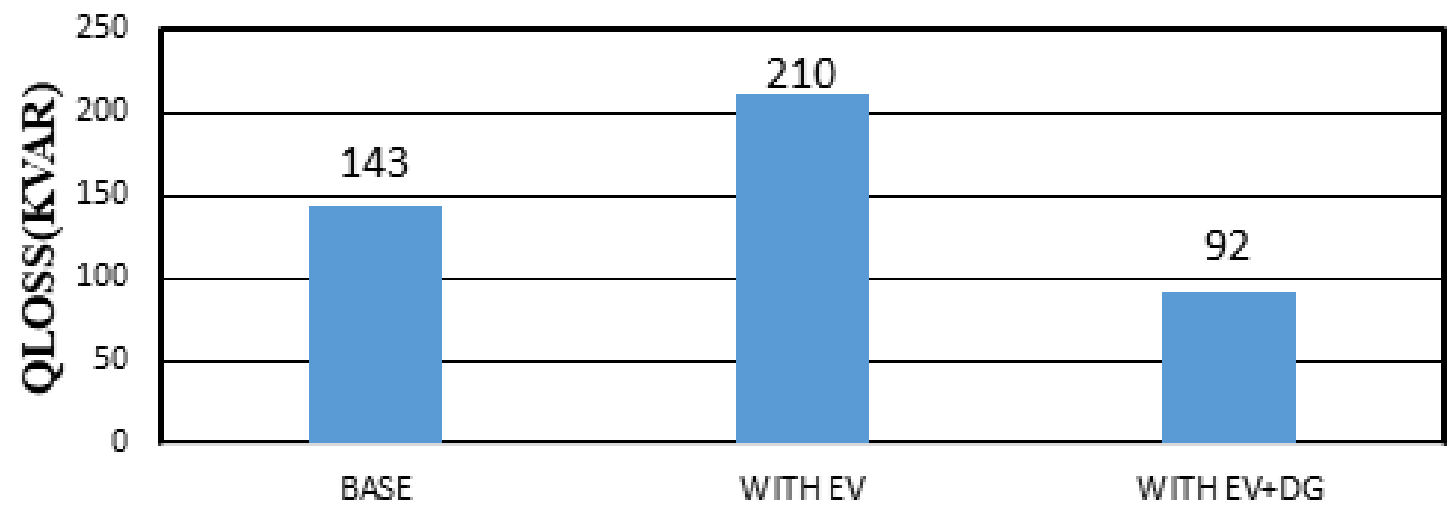

Fig 19. Reactive power losses

In Figure 19 , base case reactive power losses are 143KVAR, with integration of PEV load, losses increased to 210KVAR, after addition of 2 DGs, DG 1 with 30\% DG of load size connected at bus\#18, DG 2 with $30 \%$ of load size connected at bus\#32, reactive power losses reduced to $92 \mathrm{KVAR}$.

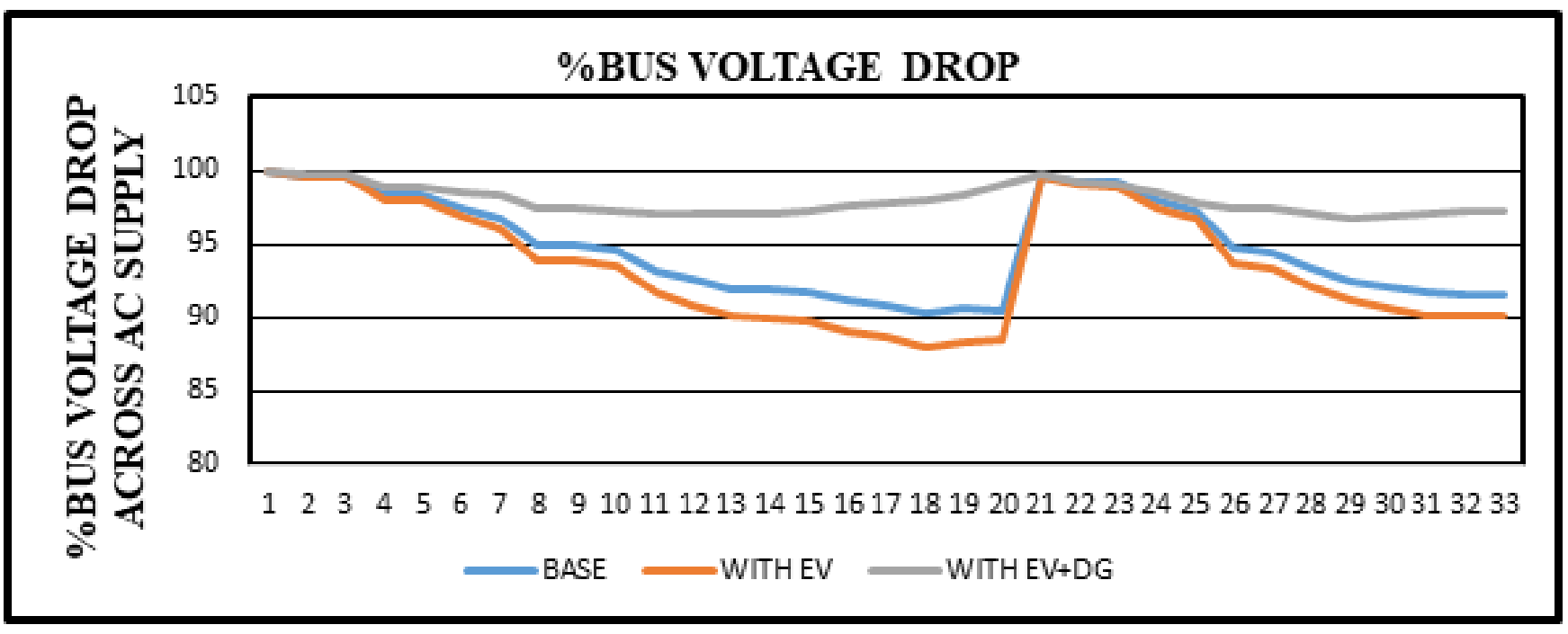

Fig 20. \%BUS voltage drop across each bus

Figure 20 shows \% Bus voltage drop across each bus in base case, after integration of PEV load and 2 DGs, DG 1 with $30 \%$ of load size connected at bus\#18, DG 2 with $30 \%$ of load size connected at bus \#32. 


\section{Results Summary}

Table 1. Comparison of power losses of different case studies

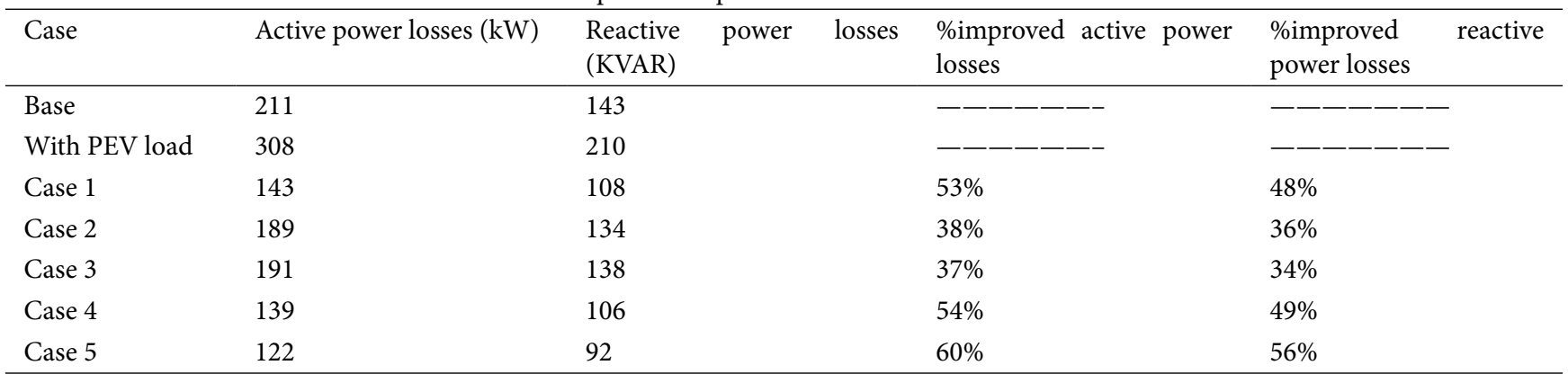

Table 1 provides the result of different case studies in terms of active and reactive power losses, convincing result shown by case 5 with $60 \%$ improvement in active power losses and 56\% improvement in reactive power losses.

Table 2. Voltage profile in per unit of different case studies

\begin{tabular}{llllllll}
\hline Minimum & Base Case & With PEV load & Case 1 & Case 2 & Case 3 & Case 4 & Case 5 \\
\cline { 2 - 7 } Voltage (p.u) & 0.9038p.u & 0.8804p.u & $0.9249 p . u$ & $0.9204 p . u$ & $0.9004 p . u$ & $0.9438 p . u$ & $0.9685 p . u$ \\
& (18thbus) & (18th bus) & (18thbus) & (33thbus) & (18th bus) & (18th bus) & (29th bus) \\
\hline
\end{tabular}

Table 2 provides the result of different case studies in terms of minimum p.u voltage, comparison of minimum p.u voltage is shown among base case, PEV load and addition of DGs. Case no.5 shows convincing result in terms of minimum p.u voltage compare to all other cases.

\section{Conclusion}

In this study, two cases are suggested to limit power losses and improve voltage profile within acceptable limit. First case is RDS with 1 DG: $30 \%$ of load size connected at bus\#18, in this case $38.43 \%$ active power, $36.42 \%$ reactive power losses are improved, further voltage is improved from 0.8804 P.U to 0.9204 P.U at weakest bus. Second suggested case is RDS with 2 DGs: DG 1 with $30 \%$ of load size connected at bus \#18, DG 2 with $30 \%$ of load size connected at bus \#32. In this case $60.1 \%$ active power losses, 56.27\% reactive power losses are improved and voltage is improved from 0.8804 P.U to 0.9685 P.U. Additionally, this study provides solution to improve system losses and voltage profile optimally by using backward-forward sweep method with minimum size of DG units that ultimately reduces the cost of distribution system.

\section{References}

1) Kongjeen Y, Bhumkittipich K, Mithulananthan N, Amiri IS, Yupapin P. A modified backward and forward sweep method for microgrid load flow analysis under different electric vehicle load mathematical models. Electric Power Systems Research. 2019;168:46-54. Available from: https://dx.doi.org/10.1016/j. epsr.2018.10.031.

2) Sadeghian O, Naari-Heris M, Abapour M, Taheri SS, Zare K. Improving reliability of distribution networks using plug-in electric vehicles and demand response. Journal of Modern Power Systems and Clean Energy. 2019;7:1189-1199. Available from: https://dx.doi.org/10.1007/s40565-019-0523-8.

3) Farahani HF. Improving voltage unbalance of low-voltage distribution networks using plug-in electric vehicles . Journal of cleaner production. 2017;148:336-346. Available from: https://doi.org/10.1016/j.jclepro.2017.01.178.

4) Ma Z, Yang N, Zou S, Shao Y. Charging Coordination of Plug-In Electric Vehicles in Distribution Networks With Capacity Constrained Feeder Lines. IEEE Transactions on Control Systems Technology. 2018;26(5):1917-1924. Available from: https://dx.doi.org/10.1109/tcst.2017.2730825.

5) Amini MH, Moghaddam MP, Karabasoglu O. Simultaneous allocation of electric vehicles' parking lots and distributed renewable resources in smart power distribution networks. Sustainable Cities and Society. 2017;28:332-342. Available from: https://dx.doi.org/10.1016/j.scs.2016.10.006.

6) Nunna HK, Battula S, Doolla S, Srinivasan D. Energy management in smart distribution systems with vehicle-to-grid integrated microgrids. IEEE Transactions on Smart Grid. 2016;9(5):4004-4016. Available from: https://doi.org/10.1109/TSG.2016.2646779.

7) Zaidi AH. Optimal electric vehicle load management for minimization of losses. In: and others, editor. 2015 Power Generation System and Renewable Energy Technologies (PGSRET). IEEE. 2015;p. 1-6. Available from: https://doi.org/10.1109/PGSRET.2015.7312215.

8) Li R, Wu Q, Oren SS. Distribution Locational Marginal Pricing for Optimal Electric Vehicle Charging Management. IEEE Transactions on Power Systems. 2014;29(1):203-211. Available from: https://dx.doi.org/10.1109/tpwrs.2013.2278952.

9) Ma Y, Zhang B, Zhou X. An overview on impacts of electric vehicles integration into distribution network. IEEE International Conference on Mechatronics and Automation (ICMA). 2015;p. 2065-2070. Available from: https://doi.org/10.1109/ICMA.2015.7237804. 
10) Mahmud K, Hossain MJ, Ravishankar J. Peak-Load Management in Commercial Systems With Electric Vehicles. IEEE Systems Journal. 2019;13(2):18721882. Available from: https://dx.doi.org/10.1109/jsyst.2018.2850887.

11) Kumar M, Nallagownden P, Elamvazuthi I. Optimal placement and sizing of distributed generators for voltage-dependent load model in radial distribution system. Renewable Energy Focus. 2017;19-20:23-37. Available from: https://dx.doi.org/10.1016/j.ref.2017.05.003. 